\title{
7 Animals as tourism stakeholders: Huskies, reindeer, and horses working in Lapland
}

\section{Introduction}

Animals in tourism engage in many forms of labor, from pulling strength to speed and riding, among others (Fennell, 2012). Animal bodies play an important role as a source of power or comfort and curiosity for tourists watching or touching them (Coulter, 2016). Moreover, it is through the emotional and embodied engagement between animals and humans (tourists and guides) that animal-based tourism experiences are co-created (Bertella, 2014; Haanpää \& García-Rosell, 2020). Although animals do not receive any direct financial compensation for their work, their human owners provide for their physiological needs (e.g. food, water, and shelter) with part of the money paid by tourists. Through their work and symbolic value, animals generate significant economic benefits for both their human owners and the tourism destinations where their labor is performed. Following Coulter's (2016) thoughts on interspecies solidarity, we argue that animals are not only tourism workers, but are also tourism stakeholders. We use an ethics of care framework (Connolly \& Cullen, 2018; Wicks, Gilbert, \& Freeman, 1994) to analyze animal tourism workers in Finnish Lapland, concluding that the human-animal relationship is largely based on contractual care by tourism entrepreneurs. As such, animal workers are seen in instrumental terms, but with concrete and distinct relations with their human owners. Customers, on the other hand, seem to view animal workers as having intrinsic value. Hence, we argue that animals become tourism stakeholders within this context through their close relationship to the traditional human stakeholder groups of customers and owners.

Considering the important role of animal labor in tourism and other organizational contexts, there is value in developing new ways of understanding stakeholders and their relationships. The tourism industry, with its complex and often messy entanglements between human and animal experiential encounters, offers a fruitful context to critically evaluate human-animal relations (e.g. Danby, Dashper, \& Finkel, 2019; Haanpää et al., 2019) and, as in this chapter, the notion of stakeholder status. Burton and Dunn (1996), along with Wicks, Freeman, and Gilbert (1994), first argued for a feminist framing in stakeholder theory in terms of establishing moral behavior, which has been somewhat overlooked in comparison to other normative moral justifications (such as rights/justice) within stakeholder theory. In this chapter, we continue the task of moving beyond the long-held deontological premises of stakeholder theory towards an understanding of stakeholders based on an ethics of care framework. Ethics of care is a core feminist framing of morality 
based on relationships, connectedness, and interdependence. In an interview, Carol Gilligan, whose book In a Different Voice (1982) was foundational for a feminist ethics of care discourse, defines this as

an ethic grounded in voice and relationships [. . .] the importance of everyone having a voice, being listened to carefully (in their own right and on their own terms) and heard with respect. An ethics of care directs our attention to the need for responsiveness in relationships (paying attention, listening, responding) and to the costs of losing connection with oneself or with others. Its logic is inductive, contextual, psychological, rather than deductive or mathematical.

(Gilligan, 2011)

Following this, our aim is to examine how animals are tourism stakeholders by applying this feminist framework to animal labor. We note that the well-being of many animals in organizations can be seen as of key strategic importance, especially within animal tourism branding itself "responsible" or "ethical," and as such, the care of the animal workers can be seen as a vital aspect of the business strategy. However, we go further than merely suggesting that animals are of key strategic importance in these contexts. We suggest that animal stakeholder status is of inherent moral value and that the human-animal relationship already existing in practice supports this understanding.

Following the recent work by Connolly and Cullen (2018) applying an ethics of care framing of animals in organizations, we explore what this means for animal stakeholder status. Whereas a deontological approach to stakeholders seeks a fair solution between competing individual rights, an ethic of care sees the interests of carers, care-givers, and cared-for as importantly intertwined rather than simply competing (Held, 2006). In organizations where animals are workers, their interests are more than just aspects of being cared-for, as upholding the animal interests is vital to the success of the business. Drawing upon interviews conducted in Finnish Lapland with animal-based tourism entrepreneurs, and upon social media content produced by international tourists and local companies, we work towards a relational understanding of stakeholders, which gives primacy to the social bonds and emotions that exist between the human and animal tourism workers. We suggest that such a framing already exists in practice among some tourism entrepreneurs, who recognize that caring well for their animals affects their business in terms of receiving positive customer reviews. In this chapter, we explore what this means for stakeholder status beyond anthropocentric objectives.

\section{Considering stakeholder theory}

\section{Who is a stakeholder?}

There are various definitions of a stakeholder, but an overarching understanding of the concept is that a stakeholder is "any individual or group who can affect or is 
affected by the actions, decisions, policies, practices, or goals of the organization" (Carroll, 1996, p. 74). The term "stakeholder" is traditionally understood to include employees, customers, suppliers, investors, government officials, competitors, local community members, and activists, among others. Phillips, Freeman, and Wicks (2003, p. 480-481) define stakeholder theory "as a theory of organizational management and ethics" which is "distinct because it addresses morals and values explicitly as a central feature of managing organizations." This ethical and moral consideration of the interests of those affected by organizational decision-making is a core tenet throughout stakeholder theory, even though there are different scholarly opinions on who "legitimate" stakeholder status encompasses (see, for example, Phillips \& Reichart, 2000). This core aspect to the theory is vital to recognize, as societal consideration increasingly acknowledges more-than-human actors (such as animals and nature) as beings and entities important not only to human survival and thriving, but with intrinsic value of their own.

Therefore, there has been much debate on whether non-human actors, such as the natural environment (which animals are traditionally merged into), should or can be considered as primordial stakeholders. Starik (1995), in his much-referenced article, made a convincing argument that the natural environment is a key stakeholder, separate from others such as suppliers, competitors, and stockholders, yet intertwined due to nature encompassing all other groups. We note that this ongoing scholarly discussion is multifaceted and based on the differing perspectives of rights, justice, and moral considerations an organization is obliged to consider. However, we suggest that in a time of impending climate change with systems of large-scale planetary disruption, it would be short-sighted (and not very ethical) to limit managerial decision-making only to human interests. In line with Gren and Huijbens (2014), we argue that the dire climate situation we face today (and in the future) is a result of overtly anthropocentric and individualist human enterprise based on outdated profit maximization ideals, something stakeholder theory, at its core, distances itself from as a moral theory (see, for example, Freeman 1984). Instead, we see that stakeholder theory presupposes the interconnectivity between sometimes diverse groups and individuals, a relational connection that feminist theory supports.

The normative justifications for stakeholder theory influence who to consider as a stakeholder. Phillips, Freeman, and Wicks (2003) conclude that there are eight different branches of the normative core of stakeholder theory. They split this core into (1) the common good, (2) feminist ethics, (3) risk, (4) integrative social contracts theory, (5) property rights, (6) Kantianism, (7) the doctrine of fair contracts, and (8) the principle of stakeholder fairness (for a detailed discussion of each, see Phillips, Freeman, \& Wicks, 2003, p. 481). The widely held anthropocentric position of not considering animals (or nature) as stakeholders finds its origins in the latter, fairness-based principles, which have generally shaped understanding of the stakeholder notion. Such an approach does not necessitate aspects of caring or emotion, upon which we and many other feminists would argue relationships are built. 
However, recent work has begun to consider animals as stakeholders due to increased societal concern for and understanding of animals in society. In Animals and Business Ethics, Smart (forthcoming) makes the case that animals should be treated as stakeholders due to them having moral status. He claims that as animals' interests are affected by organizational decisions and actions, we need to take such interests into consideration according to the core tenets of stakeholder theory (Smart, forthcoming). Following Carroll's (1996) definition at the start of this section - that it is those whose interests are affected by organizational decisions and actions who need to be considered as stakeholders - offers a logical rationale for going beyond previous business considerations and an anthropocentric focus to include animals.

\section{An ethics of care perspective on stakeholder theory}

In order to develop this consideration of animals as stakeholders, we use an ethics of care framework for working animals in tourism. Noting that animal tourism is a contested sector due to fluctuating levels of animal welfare within the global tourism industry, we suggest not only that animals benefit from being considered stakeholders, but that businesses reap benefits from the positive customer experiences that ethical interactions with animals provide in tourism destinations.

Using feminist moral ethics in stakeholder theory was first argued over 25 years ago (Burton \& Dunn, 1996; Freeman \& Gilbert, 1992; Wicks, Gilbert, \& Freeman, 1994). As stakeholder theory is based on the morals and behaviors of management, it requires moral consideration beyond justice and rights (Burton \& Dunn, 1996). Feminist moral ethics focus on caring, relationships, collaboration - many of the values which modern society is increasingly espousing, and even more so than when this framing was first suggested. This relational aspect of feminist ethics is of key importance. As Burton and Dunn (1996, p. 135) state:

Feminist ontology of humans as essentially relational beings is tied to their epistemology. They believe that humans only know through relationships. If relationships are identifying characteristics of humans, then the abstract, universal, impartial, and rational standard of what is knowledge is inadequate in decision-making.

Emotion and affect are sources of knowledge in the feminist perspective, and elements of caring are highly relevant to moral behavior (Held, 2006). We note that applying an ethics of care framing to decision-making and stakeholders does not exclude aspects of rights, duties, and justice. Rather, this is a complementary layer to stakeholder theory. As Wicks (1996) points out, there are practical objections to using only an ethics of care framing to managerial decision-making, as in a practical sense there are no guidebooks or rules on managerial caring per se.

Applying an ethics of care framework to animals in organizations is not new. However, our goal in this chapter is to apply this framing to tourism studies as a 
unique context where animal workers are vital to the sector and where caring already occurs to some degree. In a review of the organizational studies field in relation to animals, Connolly and Cullen (2018) mapped publications from 1995 to 2015 on animals within business and management studies according to an ethics of care framing in four distinct caring categories: (1) there was "contractual care" between humans and animals; (2) there was a "no care environment," where care for animals was not considered, although they were present in the context; (3) there was a "care about" animals context or topic; and (4) there was a context where animals were "care[d] for" (p. 410). The articles revealed differences in seeing animals as providing either an instrumental value to the organization or having intrinsic value in themselves. Furthermore, the relationship with the animals was seen to either be "concrete," which was "characterised by a direct and personal interaction" with animals, or "abstract," where there was "an objective distance between human and animal” (Connolly \& Cullen, 2018, p. 409). The authors found that those studies focusing on animals as instrumentally valuable in a concrete aspect applied a "contractual care" framing. These included farmers or ranchers who had a personal relationship with the animals, although these were seen in instrumental terms. Abstract notions of animals serving instrumental values were seen in the "no care environment," which included animals in entertainment, animals as research tools, and other forms of commodifying animals. On the other hand, animals with intrinsic value were seen in abstraction in articles focused around topics related to ethical consumption, animal advocacy, and sustainability in the "care about" category, while the fourth category, "care for," was focused on animal shelter workers and aspects related to companion animals who were seen to have intrinsic value and enjoyed a concrete human-animal relationship.

In the categorization (which included 185 peer-reviewed articles), 10 articles were focused on the tourism sector. Most of these (six articles out of 10) involved a "care about" relationship with animals. Within this, the subcategory of sustainability or conservation aspects in relation to animals was dominant (Higham \& Shelton, 2011; Orams, 2002; Reynolds \& Braithwaite, 2001). The second most dominant view from an ethics of care perspective was a "no care" relationship (three articles of ten), where animals were viewed as a marketing tool (Okello, Manka, \& D’Amour, 2008), seen as a commodity (Galloway \& Lopez, 1999), and seen as a source of disease (Lee \& Chen, 2011). Only one article had "contractual caring” by farmers as its focus and, interestingly, none of the reviewed articles found a "care for" framing within tourism. Such a categorization is useful to apply to animal tourism workers, and we apply this ethics of care framing in the specific context of Finnish Lapland to better understand the situation in practice. 


\section{Animal workers in tourism: Husky, reindeer, and horse tours in the winter wonderland}

Animal workers are vital to much of the tourism industry, which relies on encounters with nature and animals for unique tourism experiences in holiday destinations. Coulter (2016) creates a case for animals as workers in describing the entanglements that exist between humans and animals at work. She comments in her book Animals, Work and the Promise of Interspecies Solidarity (2016, p. 11) that "a large majority of labor researchers fail to see that humans are but one of many species in any given space and community, that many humans work with animals, that humans depend upon the broader ecological web for subsistence and survival, and that human, animal, and environmental well-being are inextricably connected.” Coulter calls this framework "interspecies solidarity" to account for humane work which includes "jobs that are good for both people and animals" (p. 163). She concludes that work which exploits animals is often detrimental to humans and the environment, too (for example, slaughterhouse work, which impacts all organizational actors negatively). In this way, focusing on the well-being of humans and animals in solidarity benefits all involved, as the welfare of all actors is interlinked (see García-Rosell \& Hancock, forthcoming). This inter-relational conceptualization links to our framing of animals as stakeholders in tourism, as the human-animal relationship is at the core of the context of the Finnish Lapland destination.

Finnish Lapland is the northernmost province of Finland and the European Union. With only 3.5\% of Finland's population but about 30\% of Finland's total area, Lapland is by far the least densely populated region in Finland, and a rapidly growing wilderness and nature-based tourism destination. The number of annual registered overnight stays in Lapland is 3 million (Regional Council of Lapland 2019). As a tourism destination, Lapland attracts tourists from around the world, particularly in the winter season between December and March. Although most tourists come from European countries, the number of Asian tourists has increased sharply in recent years. In Lapland, tourists engage in winter activities such as viewing the northern lights (or Aurora Borealis), driving snowmobiles, visiting Santa Claus, and riding reindeer sleighs and dog sleds. According to a recent study (García-Rosell \& Äijälä, 2018), more than half of the tourists traveling to Finnish Lapland consider the winter landscape and animal-based activities the main reasons to visit this Nordic destination.

Animal-based tourism services, such as dog sledding and reindeer sleigh tours, are some of the most popular activities among tourists (García-Rosell \& Äijälä, 2018). Indeed, these two activities form part of the ritualized pattern that international tourists follow when visiting Lapland. A recent study calculated that there are 4,000 dogs and 750 reindeer working in the tourism industry in Lapland, generating an annual turnover of approximately 15 million euros (García-Rosell \& Äijälä, 2018). 
However, this is an estimate, as their actual number may be higher, especially the number of dogs. There are also 150 horses working in tourism, but these tend to be more popular among the domestic Finnish visitors than international ones. Although the reindeer is an icon of Lapland and an essential element of the Christmas narratives, it is husky activities that are growing in popularity. In 2017, for the first time, husky safaris surpassed snowmobile safaris as the number one tourism activity in Lapland. Similar to human employees, the working and resting hours of these animal workers are carefully planned by their owners, and most of their work is done during the winter period (Ojuva, 2018).

Huskies in Lapland live in outdoor dog kennels with populations that can vary from a dozen to 500 dogs. The number of all-year-round kennels in the Finnish Lapland area is close to 50. In addition, mushers (dog handlers) come with their dogs from other parts of Finland and Europe to work in the industry during the peak season (December-February). The number of seasonal mushers is difficult to determine due to a lack of official statistics. Most of the sled dogs in Lapland are Alaskan huskies, which are a mix of different northern breeds chosen particularly for their pulling skills. There are also Siberian huskies, which is the breed commonly depicted in the commercial marketing and internet material for tours. Husky safaris can range from short $(0.5-2 \mathrm{~km})$ to medium-length $(10-40 \mathrm{~km})$ and multi-day rides (two to eight days). The sleds are pulled by four to six dogs depending on the size and weight of the musher and passenger(s). Almost all of the safaris are organized in the same way. Firstly, independent of the length of the safari, tourists receive driving and safety instructions before entering the kennel. Secondly, driving instructions are provided by a guide demonstrating how to handle the sled and the team of dogs. Thirdly, the tourists are guided towards the sleds to get ready for the start of the safari (Figure 7.1). Depending on the type of safari, during the ride there are different stops where the driver can swap places with the passengers. In this way, all the adult tourists have an opportunity to drive the sled. When the safari is over, tourists can take a tour of the kennels and learn more about and cuddle the dogs.

For many tourists, just seeing reindeer along the road or while walking through the forest in the snow is part of the unique Lapland tourism experience. Like husky tours, reindeer sledging is very popular with tourists of all ages throughout the winter season, and in the Christmas season in particular (see García-Rosell \& Hancock, forthcoming). Reindeer work may take different forms (see Hoarau-Heemstra, 2018; Nieminen, 2014). Some reindeer are enclosed within the boundaries of the reindeer farms, where tourists can approach and feed them, as well as photograph themselves with the exotic and mythical animals. Other reindeer work as draft animals, pulling sleighs in activities. In the tourism industry, reindeer perform the roles of both workers and objects of the tourist gaze (Urry, 1990). The reindeer working as draft animals are castrated male reindeer who have undergone a long period of training, lasting between four and five years. In comparison to dog sledding, tourists do not need to handle the sleigh. These tours may take place in an enclosure where the reindeer 


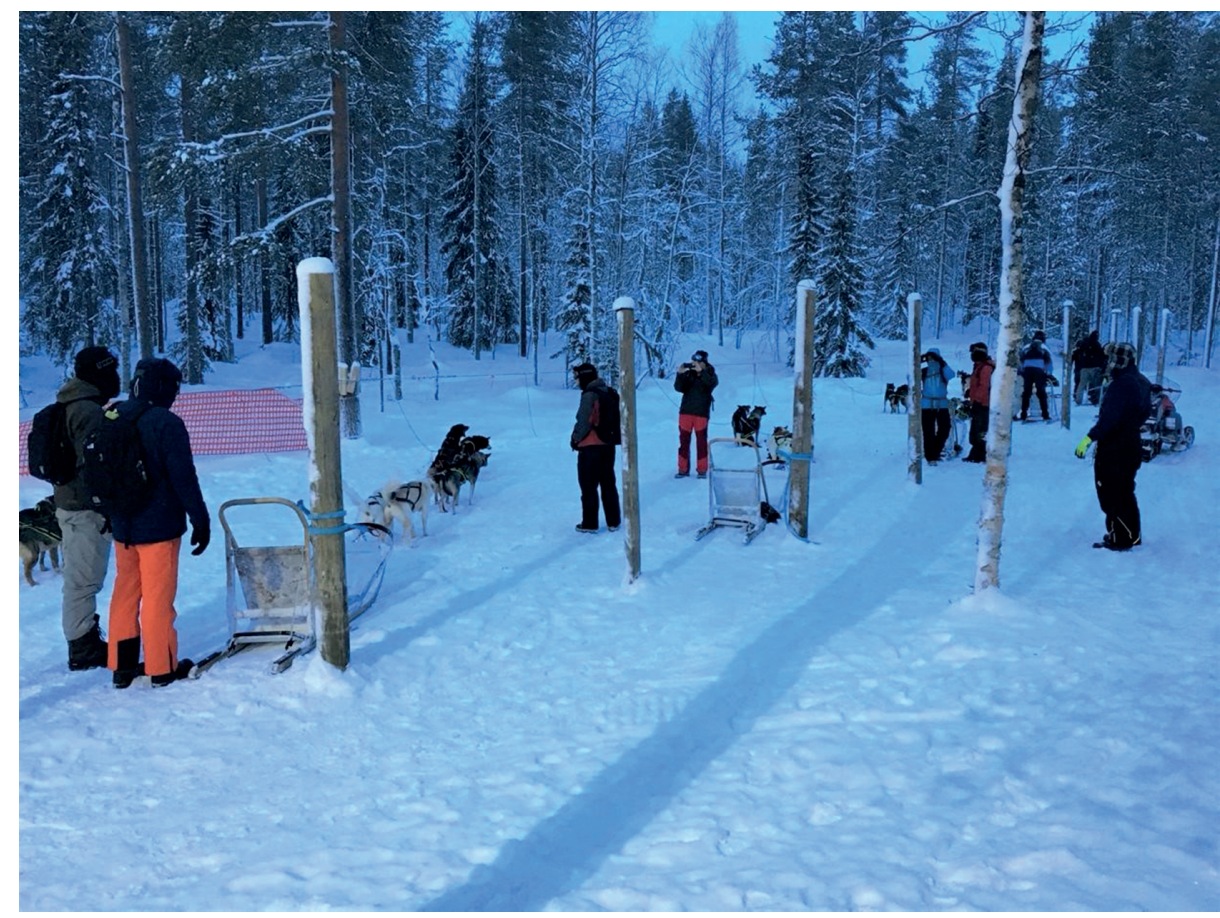

Figure 7.1: Preparing for the start of the sled dog safari.

Source: Author.

follow a predetermined track (Figure 7.2). In case of longer tours, a guide will drive in front of all sleighs, leading and setting the pace of the tour. Reindeer tours may last from half an hour to a couple of hours. Female reindeer are not used as draft animals due to the gestation period that takes place during the winter season. Reindeer only pull sleighs during the winter season from December to April, and most of the tourism reindeer roam free in the pastures and forest of Lapland in the summer. A small number of reindeer stay at the reindeer farm during the summer months for tourist "meet and greets." As part of the reindeer herding annual cycle, female and unskilled male reindeer are slaughtered for human consumption as in poronkäristys (traditional sautéed reindeer) and their bones, antlers, hides, and other body parts used to produce traditional tourist souvenirs, (see García-Rosell \& Hancock, forthcoming; Hoarau-Heemstra, 2018).

Although horses are less popular among international tourists, there are several horse stables offering horseback riding in Lapland. Some Finnish tourists prefer to experience horse-riding in Lapland, rather than the husky or reindeer tours which are more popular with international visitors. These tourists vary in their experience; some domestic tourists are advanced riders, while others may have limited riding 


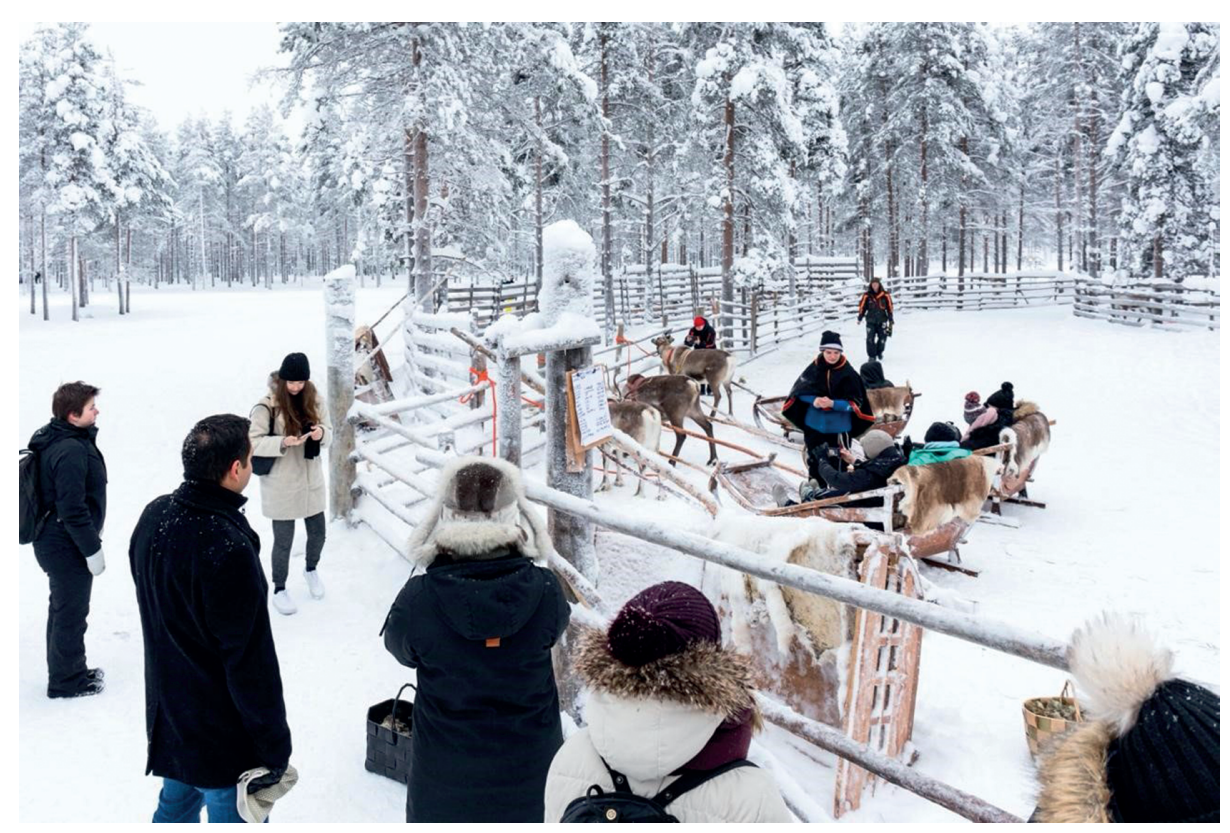

Figure 7.2: Reindeer sleigh rides at reindeer farm.

Source: Marko Junttila. Used with permission.

experience. Safety and winter wear is often made available to visitors, and they will have at least one experienced guide during the riding tour. Most horses used for horseback riding in Lapland are Finnhorses or Icelandic horses. The Finnhorse is a domestic horse of Finland and serves as the country's official national horse breed. Icelandic horses are also popular in tourism activities in Lapland. Both horse breeds are capable and reliable mounts, well adapted to the harsh climate and terrain of the region. As both the Finnhorses and Icelandic horses grow a thick winter coat, they can tolerate surprisingly low temperatures. The horses usually work in trail riding of different lengths from one hour to a half day or entire day. Some companies also offer longer trail rides which include overnight stays in cabins along the trails. The horse stables in Lapland have between five and 20 horses. Although stalls are common practice, the number of loose stables is growing in Lapland (Figure 7.3). A loose stable allows horses to live in a herd and move freely both outdoors and indoors. As with the huskies and reindeer, the work shifts of horses are monitored and the individual character and strength of horses is considered in shift planning by the human caretakers (Kähkönen, 2018). 


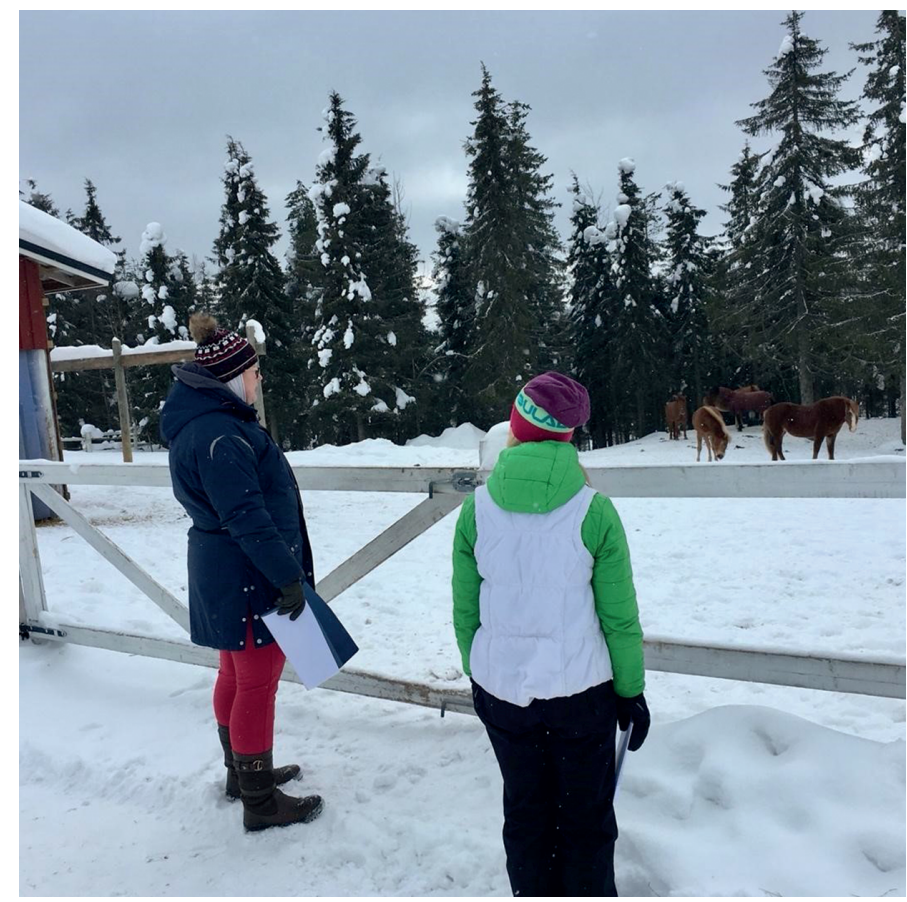

Figure 7.3: Loose stable at horse farm.

Source: Author.

\section{Animal stakeholdership: Social bounds and emotions}

In this chapter, we aim to illustrate animals becoming tourism stakeholders by applying a feminist normative core of stakeholder theory (Burton \& Dunn, 1996; Wicks, Gilbert, \& Freeman, 1994), specifically that of ethics of care. The excerpts used in this chapter come from interviews with animal-based tourism entrepreneurs and from social media content generated by Lapland tourists and service providers. The data were gathered within the scope of two parallel two-year EU-funded research and development projects focusing on animal welfare as part of responsible tourism in Finnish Lapland. Data collection was conducted by four researchers, one project worker, and five Bachelor's/Master's students. The first author of this chapter was one of the researchers and the leader of the team. During the early stage of the two projects, the team collected documentary material about the topic in general and in relation to Finland and Lapland in particular, implemented a survey with tourists, conducted participant/non-participant observations, and attended several meetings in the premises of approximately 20 different animal-based tourism companies. Based on 
this preliminary work, companies that showed a high level of commitment towards animal welfare were selected to be interviewed. The social media data were collected in the last stage of the projects to complement the data gathered by examining online discussions related to animal welfare in Lapland.

A total of 11 semi-structured interviews with the owners of husky kennels and reindeer and horse farms operating in Finnish Lapland were conducted by one researcher and the project worker, occasionally accompanied by one or two Bachelor's students, between March 2016 and May 2017. The interviews took place in the premises of the companies and concentrated particularly on the treatment and welfare of their animals in relation to their business operations, customers, and communication strategies. The interviews lasted approximately 60-90 minutes; they were audio recorded and then carefully transcribed. The user-generated social media content included publicly available comments, reviews, and discussions created during 2016, 2017, and January 2018. The content used relates to 45 Lappish tourism companies and consists of 304 reviews systematically collected from Facebook, Instagram, TripAdvisor, and YouTube during January and February 2018 by one Master's student under the supervision of the first author of the chapter (Klos, García-Rosell, \& Haanpää, 2018). The companies were selected based on their social media presence from a list of 158 animal-based tourism service firms operating in Lapland (Bohn, García-Rosell, \& Äijälä, 2018). Furthermore, only companies which offer animalbased activities involving sled dogs, reindeer, and horses were considered in the study. Destination management companies that sell animal-based activities were also included in the study due to their significant presence on social media.

The data were thematically analyzed relying on content analysis (Bengtsson, 2016). The interview data were divided according to five main themes: animal welfare, working relationships, customer relationships, communication, and safety. The social media content categories were established inductively in relation to the collected data. By carefully reading through the social media data, we were able to identify two main themes: animals considered in the comments and animals omitted in the comments. In this chapter, we focus on the theme of animals considered in the comments, which was divided in four sub-themes: animal welfare, animal appearance, animal behavior, and animals as educational resource. After discussing and reflecting on the data collaboratively, we identified passages reflecting the care perspective on human-animal stakeholder relationships. Next, we present the results of the analysis by first discussing animal stakeholder status being embedded in the social bonds with their owners, and then discussing the emotions and social bonds evolving through customer interactions. 


\section{Animal stakeholder status embedded in social bonds with owners}

Using an ethics of care perspective on this data draws attention to relationships as morally worthy and of value in human-animal interactions. Animal-based tourism entrepreneurs tend to stress a caring relationship when talking about their animals. As one reindeer tourism entrepreneur points out:

These reindeer are our colleagues and, like, we know every reindeer personally [. . . ] and [their] characteristics, in a way that it is our partner and not [just] a tool.

(Excerpt 1, Interview Reindeer Farm)

This focus on it being a collaborative effort, a form of partnership, fits well with feminist moral theory, as well as the interspecies solidarity of Coulter (2016). This is particularly relevant when further describing the relationship between animal-based tourism entrepreneurs and their animals. As Excerpt 2 shows, entrepreneurs tend to give preference to those animals with whom they have a close relationship. This follows the ethics of care framing, as those we relate to are shown higher concern and care than those further away from us (similar to social bonds) (Held, 2006). For example, as one of the reindeer tourism entrepreneurs expresses:

When a reindeer becomes too old, we might send it to the slaughterhouse, but it can also happen that we put it down ourselves and take it out into the forest [. . . ] but I wouldn't feel like selling an old sledge reindeer as meat, because it has been working for so many years and it has been an everyday workmate [. . . ] so it [what happens to aging animal workers] depends a bit on the situation.

(Excerpt 2, Interview Reindeer Farm)

This relationship may not necessarily eliminate harm, but it may give certain "privileges" to animals who share a special bond with the owners of the company. In terms of relating both interview excerpts to the ethics of care- categorization of Connolly and Cullen (2018), it seems that the reindeers and their owners have a contractual care relationship here. As such, it seems that some of the animal workers in this specific tourism destination might benefit from a closer relationship than in other contexts: although these are special connections with certain individual animals or groups of animals, it does not give them intrinsic value as the "caring for" categorization would. For example, the quote above reveals that the entrepreneur would not be able to sell a "workmate" as meat once he is "too old" to work by pulling a sledge, but may instead be able to kill it themselves and "take it out into the forest." The reindeer is seen in instrumental terms as he is killed once "spent," suggesting the commodification of the animal's utility over an inherent intrinsic value (Hughes, 2001), which the animal shelter and companion animal category in Connolly and Cullen's (2018) categorization focused on. Linguistics also matter in revealing this instrumental relationship. The entrepreneur refers to the reindeer as "it" rather than he, suggesting a distancing and objectification of the animal apart from human workers. 
The emphasis on collaboration and cooperation - characteristic of the feminist perspective in stakeholder thinking, as described by Wicks, Gilbert, and Freeman (1994) - is evident in the ways in which the human-animal relationships are developed in the animal-based tourism companies. Some describe that there is a mutual understanding between the humans and the animals that makes things work, as one of the horse entrepreneurs explain:

As long as the horse is lively and cooperative, when you tell it "let's go for a ride" and it's willing to come, you know it's fine. You know it when a $600 \mathrm{~kg}$ creature isn't willing to come. And if it has an appetite for its food, I figure the animal is doing well. And when you know approximately its limits, you make sure not to bring the horse close to them. We don't want that to happen, as everything would stop working.

(Excerpt 3, Interview Horse Farm)

The ethics of care framework can easily be applied to the context, although to different degrees in terms of its practical application. It seems that caring, relationship-building and cooperation serve as mechanisms for the humans and animals to learn from each other, build trust, and find ways of working together in order to deliver the service - the animal tour experience. This aspect of collaboration in the feminist framing seems to transcend specific species in the Lapland context, applying to horses as well as dogs as animal workers.

You've got to think about it in the way that you treat each dog as if it was your own. Because when it's your own dog, it likes you and doesn't run away with its tail between its legs but comes to your side. Only then is it easy to deal with them, when they like to be with you and only then do they run the best and work well [. . . ] The same with the horses. It's not going to work by beating it with a stick. On the contrary, you have to work on building trust in the horse so that when it comes to a difficult situation, the horse will trust you and follow your instructions.

(Excerpt 4, Interview Kennel and Horse Farm)

Relationships built in an animal-based tourism context seem not only to contribute to facilitating close proximity between human and animal workers, but also to cultivating the virtues of care, respect and self-mastery (see Anthony, 2012). From this perspective, an ethics of care provides an opportunity for human workers to remain close to the outcome of their decisions and those animals that will be directly affected by them (Connolly \& Cullen, 2018). This is reflected in the following quote from one of the sled dog entrepreneurs:

My husband is very good at spotting dogs that aren't performing well in the safari. Sometimes you need to change the dogs during the trip. It's very important that you know how to do it. If one of our dogs doesn't tolerate a customer, for example, because they brake wrong or ride too fast downhill, my husband stops the safari and replaces the dog with one that's better at keeping up with that type of customer [. . . So, we are pretty good at noticing these individual aspects.

(Excerpt 5, Interview Kennel and Horse Farm)

This quote shows the importance of reading the dogs' behavior and knowing their different temperaments with difficult customers. Without this mutual respect and understanding between the sled dog entrepreneur and their dogs, the dogs would 
suffer at the hands of tourists who, more often than not, are unskilled in driving sleds and handling dogs. In this way, it is beneficial both for the dogs, who are replaced if not "performing well," and for the business owner, who inevitably will gain better customer reviews from positive sled experiences. From the dogs' perspective, dealing with such a variety of customers, it is essential that the owners pay attention to reading customers and their behaviors. One could ask whether it is appropriate for all customers to be given the opportunity to handle a dog sled, and at what point the owners take over if the customer is not able to handle themselves appropriately; however, such aspects were not available in our data. But seeing the sled dogs as key stakeholders, with their own limitations and strengths, may lead to overall better experiences for the humans and animals involved, in addition to positively affecting the business outcomes.

\section{Animal stakeholder status embedded in customer social bonds and emotions}

Another human-animal relationship that exists in this context is the social bond between animal and customer. The customer comes to experience an animal adventure at the tourism destination and therefore leaves with an emotive human-animal experience. Customers are already considered key stakeholders in most service businesses, and customer satisfaction is usually upheld as a barometer for good business dealings. Within the tourism industry, online tourist customer reviews play a key role in generating new business, with social media comments used to tell experiential stories as part of tourism companies' communication strategies. We use quotes from both company-generated content and customer reviews to analyze the ethics of care framing for animal stakeholder status based on the social bond with the customer. We contend that the social bond with customers (a key traditional stakeholder group) and the emotional aspects of human-animal interactions are what assigns stakeholder status to animals. Feminist moral theory acknowledges emotions as key areas of knowledge (Burton \& Dunn, 1996), and here we see the use of such aspects for commercial benefits, as well as underpinning the experience. Emotions are key marketing tools, and positive aspects regarding the animals and their welfare are important for more business.

The staff are very helpful and accommodating and they really care for their dogs. I was a bit sceptical of these kinds of things [animals' quality of life], but the company really opened my eyes to the world of sled dogs. These beautiful dogs love what they do and they are properly cared for and very much loved.

(Social Media Content, Customer A)

Honestly, the thing that I loved the most about this experience was how much the business revolves around the dogs. The owner has a special formula for their food, supplemented with a variety of meats. The staff members know the names of all 95 dogs, and spend 2.5 years working with 
them before they ever pull a sled, and their work schedule is determined by the dog's physicality [. . . ] dogs who need more down time get it, while dogs that love to run get sent out more. They treat their dogs like family, and it was really heart-warming to get to see it.

(Social Media Content, Customer B)

I did a lot of research into which husky safari to choose and wanted to book with one which had good ethics and clearly cared for the dogs. From the moment I started corresponding with [the owner of the kennel], I knew that this was important to him and the farm also! The dogs clearly loved working and enjoyed some cuddles afterwards.

(Social Media Content, Customer C)

All three accounts demonstrate the importance of the dogs' well-being. They show how some animal-based tourism customers to this particular destination look for, research, and evaluate whether the animals they encounter when buying the animal experiences are well cared for and "loved" as "family." Although it would be interesting to know more about what "good ethics" means for Customer C and whether all reviews (and not only positive ones) are available to customers, the comments show the importance of "good" animal care from the customers' perspective. In this way, from an ethics of care perspective, the customer's social bond to the dog becomes more of a "care about" framing rather than the overt "contractual care" seen in the owner-dog relationship earlier.

However, in the company-generated content, there were also aspects of owners "caring for" their dogs. The following quote is from a company Facebook page demonstrating a "care for" relationship with an ex-sled dog by adopting him to a home rather than euthanizing him, which is a normal and fully legal procedure in Finland and most countries. When a sled dog is unable to work due to behavioral issues (being too timid or aggressive) or physiological issues (being too weak to pull the sled or too old), the kennel can legally euthanize the dog. One of the most controversial aspects of dog sledding is that euthanasia is used to a large degree to manage dogs who are not good workers. As shown in the previous section, many view the animals from a "contractual caring" perspective, which this management style would support. Creating systems of adoption or other alternatives to euthanasia would require owners to shift more towards the "caring for" perspective. The following sled entrepreneur wants to show that responsible animal tourism is possible through applying a "care for" aspect, intrinsically valuing the dogs for themselves, rather than purely for the value that the business generates from them. As such, they use adoption as an alternative to euthanizing the dogs.

Miyagi is super cuddly and loves attention and lots of food. Miyagi was castrated a few years ago because he could be a bit aggressive towards other dogs. He is much better now, but sometimes still snaps out of excitement, which can irritate his running partner and lead to fights, but he doesn't really mean any harm. He simply lacks a bit of social competence. He is a dog that it's hard not to like, and he certainly loves people. This big-eared loveable goofball has been a favourite of many guides over the years, but this year he finally hit the jackpot when he met Alva who came from Sweden to work as a guide at the beginning of March. Around this point in the season, Miyagi (who was never really a very good sled dog) decided he would 
rather be on a couch than pulling a sled, and was fast-tracked onto our adoption list. Alva had already fallen in love with his goofy personality, and decided to take him on. In a few days, Alva and Miyagi will begin their journey to their new home outside Stockholm where they will live and work in a horse stable.

(Social Media Content, Company H)

Such an account clearly shows a different type of agency of the dog who is given intrinsic value beyond his ability to work (see Hughes, 2001).

\section{Conclusions}

In this chapter, we suggest that applying an ethics of care framing to animal workers in tourism shows that there are already degrees of animal stakeholder status in the industry. Relying on empirical data from animal-based tourism firms operating in Finnish Lapland, we demonstrate that what makes a husky, reindeer, or horse a tourism stakeholder in the first place are the social bonds and emotions that they share with human stakeholders, such as their owners and customers. These findings are portrayed below in Figure 7.4, adapted from Connolly and Cullen (2018). We find that the human-animal social bond with owners is predominantly based on what Connolly and Cullen label "contractual care," whereby the human-animal relationship is distinct but often instrumental.

Abstraction

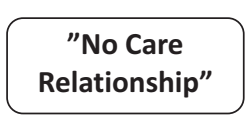

"Care About"

Animal-Based tourism

customers

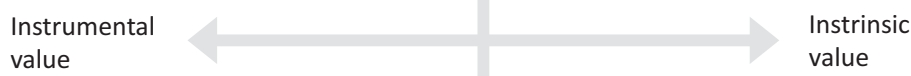

\section{Animal-Based tourism \\ entrepreneurs}

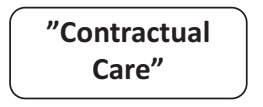

"Care For"

Concretization

Figure 7.4: Ethics of care framework applied to animal-based tourism in Lapland.

Source: Adapted from Connolly and Cullen (2018, p. 410) 
On the other hand, the social bonds and emotions of customers' reviews are based on what Connolly and Cullen label "care about," where the animal has greater intrinsic value, yet there is still an abstract or indirect relationship with the animals. We found that there are some animal tourism entrepreneurs who are moving towards Connolly and Cullen's “care for” categorization of the human-animal relationship through using adoption programs for dogs in retirement or animal workers with poor performance. We find this to be a positive move, whereby the animal workers truly gain agency and value beyond their direct commercial value. Nevertheless, animal work is still not covered by labor legislation, which is exclusively reserved for human workers. Indeed, the question remains: should the animal workers not have some of the benefits human workers enjoy beyond their working role - for example, pension plans, sickness benefits, and value beyond utility? These are some of the ethical considerations that need to be addressed if we truly wish to employ animal workers in our businesses. Moving towards a "care for" relationship, where each animal's unique individuality and right to life beyond commercial gains are ensured, would surely lead to more authentic and responsible human-animal interactions in tourism (see Fennell, 2014). This could lead to further interspecies solidarity and humane work (Coulter 2016), which could create new ways of relating to and with animals at work.

\section{References}

Anthony, R. (2012). Building a Sustainable Future for Animal Agriculture: An Environmental Virtue Ethics of Care Approach within the Philosophy of Technology. Journal of Agricultural and Environmental Ethics 25, 123-144.

Bengtsson, M. (2016). How to Plan and Perform a Qualitative Study using Content Analysis. NursingPlus Open 2, 8-14.

Bertella, G. (2014). The Co-creation of Animal-based Tourism Experience. Tourism Recreation Research 39(1), 115-125.

Bohn, D., García-Rosell, J. C., \& Äijälä, M. (2018). Animal-based Tourism Services in Lapland. University of Lapland, Multidimensional Tourism Institute. Available at www.matkailuelaimet.fi.

Burton, B. K. \& C. P. Dunn. (1996). Feminist Ethics as Moral Grounding for Stakeholder Theory. Business Ethics Quarterly 6(2),133-147.

Carroll, A. B. (1996). Business and Society: Ethics and Stakeholder Management. 3rd edition Cincinnati, $\mathrm{OH}$ : Southwestern.

Connolly, L., and J. G. Cullen. (2018). “Animals and Organisations: An Ethic of Care Framework.” Organization \& Environment 31(4), 406-424.

Coulter, K. (2016). Animals, Work, and the Promise of Interspecies Solidarity. New York: Palgrave Macmillan.

Danby, P., K. Dashper, \& R. Finkel. (2019). “Multispecies Leisure: Human-Animal Interactions in Leisure Landscapes.” Leisure Studies 38(3), 291-302.

Fennell, D. (2012). Tourism and Animal Ethics. Abingdon: Routledge.

Fennell, D. (2014). “Exploring the Boundaries of a New Moral Order for Tourism's Global Code of Ethics: An Opinion Piece on the Position of Animals in the Tourism Industry." Journal of Sustainable Tourism 22(7), 983-996. 
Freeman, E. (1984). Strategic Management: A Stakeholder Approach. Boston, MA: Pitman. Freeman, R. E. \& Daniel R. Gilbert. (1992). "Business Ethics and Society: A Critical Agenda." Business \& Society 31, 9-17.

Galloway, G. \& K. Lopez. (1999). "Sensation Seeking and Attitudes to Aspects of National Parks: A Preliminary Empirical Investigation.” Tourism Management 20, 665-671.

García-Rosell, J. C. \& M. Äijälä. (2018). “Animal-based Tourism in Lapland.” In Animal Welfare in Tourism Services: Examples and Practical Tips for the Well-being of Animals used for Tourism in Lapland, edited by J. Ojuva, 10-24. Rovaniemi: Lapland University of Applied Sciences.

García-Rosell, J. C. \& P. Hancock. (Forthcoming). "Working Animals, Ethics and Critical Theory.” In Animals and Business Ethics, edited by Natalie Thomas. Cham: Springer.

Gilligan, C. (1982). In a Different Voice: Psychological Theory and Women's Development. Boston, MA: Harvard University Press.

Gilligan, C. (2011), July 16. "Care Ethicist Network Interview with Carol Gilligan.” https://ethicsof care.org/carol-gilligan/

Gren, M. \& E. Huijbens. (2014). "Tourism and the Anthropocene." Scandinavian Journal of Hospitality and Tourism 14(1), 6-22.

Haanpää, M. \& J. C. García-Rosell. (2020). "Understanding Performativity and Embodied Tourism Experiences in Animal-Based Tourism in the Arctic." In The Routledge Handbook of Tourism Experience Management and Marketing, edited by S. K. Dixit, 229-237. London: Routledge.

Haanpää, M., T. Salmela, J. C. García-Rosell, \& M. Äijälä. (2019). “The Disruptive 'Other’? Exploring Human-Animal Relations in Tourism through Videography." Tourism Geographies. https://doi.org/10.1080/14616688.2019.1666158

Held, V. (2006). "The Ethics of Care." In The Oxford Handbook of Ethical Theory, edited by D. Copp, 537-566. Oxford: Oxford University Press.

Higham, J. E. S. \& E. J. Shelton, (2011). "Tourism and Wildlife Habituation: Reduced Population Fitness or Cessation of Impact?" Tourism Management 32, 1290-1298.

Hoarau-Heemstra, H. (2018). "A Life Worth Living: Reindeer in Nordic Tourism Experiences.” In Animals, Food and Tourism, edited by C. Kline, 113-128. London: Routledge.

Hughes, P. (2001). "Animals, values and tourism - structural shifts in UK dolphin tourism provision.” Tourism Management 22, 321-329.

Kähkönen, O. (2018). "Animal-based Tourism in Lapland.” In Animal Welfare in Tourism Services: Examples and Practical Tips for the Well-being of Animals used for Tourism in Lapland, edited by J. Ojuva, 10-24. Rovaniemi: Lapland University of Applied Sciences.

Klos, D., J. C. García-Rosell, \& M. Haanpää. (2018). "Analysis of User-generated Social Media Content related to Animal-based Tourism Activities in Lapland.” Accessed May 20, 2020, www.animaltourismfinland.com

Lee, C., \& C. Chen. (2011). "The Reaction of Elderly Asian Tourists to Avian Influenza and SARS." Tourism Management 32, 1421-1422.

Nieminen, M. (2014). Poro-Reindeer. Helsinki: Books on Demand.

Ojuva, J. (2018). Animal Welfare in Tourism Services: Examples and Practical Tips for the Well-being of Animals used for Tourism in Lapland. Rovaniemi: Lapland University of Applied Sciences.

Okello, M. M., S. G. Manka, \& D. E. D 'Amour, (2008). “The Relative Importance of Large Mammal Species for Tourism in Amboseli National Park, Kenya." Tourism Management 29, 751-760.

Orams, M. B. (2002). "Feeding Wildlife as a Tourism attraction: A Review of Issues and Impacts." Tourism Management 23, 281-293.

Phillips, R. A. \& J. Reichart. (2000). "The Environment as a Stakeholder? A Fairness-based Approach." Journal of Business Ethics 23, 185-197.

Phillips, R. A., Freeman, R. E., and Wicks, A. C. (2003). What Stakeholder Theory Is Not. Business Ethics Quarterly 13(4), 479-502. 
Regional Council of Lapland. (2019). Lapin matkailustrategia 2020-2023 [Lapland Tourism Strategy 2020-2023]. Lapin liiton julkaisuja Serie A, No. 54. Rovaniemi: Regional Council of Lapland. Reynolds, P. C., \& D. Braithwaite. (2001). "Towards a Conceptual Framework for Wildlife Tourism." Tourism Management 22, 31-42.

Smart, J. (Forthcoming). "Animals as Stakeholders." In Animals and Business Ethics, edited by Natalie Thomas. Cham: Springer, accessed May 1, 2020, https://philarchive.org/archive/ SMAAAS-2

Starik, M. (1995). "Should Trees have Managerial Standing? Toward Stakeholder Status for Nonhuman Nature." Journal of Business Ethics 14(3), 207-217.

Urry, J. (1990). The Tourist Gaze. London: Sage.

Wicks, A. C. (1996). "Overcoming the Separation Thesis: The Need for a Reconsideration of Business and Society Research." Business \& Society 35(1), 89-118.

Wicks, A. C., D. R. Gilbert, \& E. Freeman. (1994). "A Feminist Reinterpretation of the Stakeholder Concept.” Business Ethics Quarterly 4(4), 475-497. 
